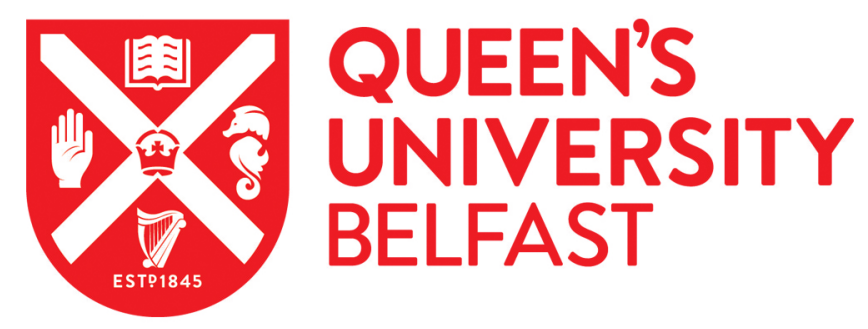

\title{
Influence of deprivation and rurality on patient-reported outcomes of men living with and beyond prostate cancer diagnosis in the UK: a population-based study
}

Smith, L., Downing, A., Norman, P., Wright, P., Hounsome, L., Watson, E., Wagland, R., Selby, P., Kind, P., Donnelly, D., Butcher, H., Huws, D., McNair, E., Gavin, A., \& Glaser, A. W. (2020). Influence of deprivation and rurality on patient-reported outcomes of men living with and beyond prostate cancer diagnosis in the UK: a population-based study. Cancer Epidemiology, 69. https://doi.org/10.1016/j.canep.2020.101830

Published in:

Cancer Epidemiology

Document Version:

Peer reviewed version

Queen's University Belfast - Research Portal:

Link to publication record in Queen's University Belfast Research Portal

\author{
Publisher rights \\ (C) 2020 Elsevier Ltd. \\ This manuscript version is made available under the CC-BY-NC-ND 4.0 license http://creativecommons.org/licenses/by-nc-nd/4.0/,which \\ permits distribution and reproduction for non-commercial purposes, provided the author and source are cited.
}

\section{General rights}

Copyright for the publications made accessible via the Queen's University Belfast Research Portal is retained by the author(s) and / or other copyright owners and it is a condition of accessing these publications that users recognise and abide by the legal requirements associated with these rights.

Take down policy

The Research Portal is Queen's institutional repository that provides access to Queen's research output. Every effort has been made to ensure that content in the Research Portal does not infringe any person's rights, or applicable UK laws. If you discover content in the

Research Portal that you believe breaches copyright or violates any law, please contact openaccess@qub.ac.uk. 
Influence of deprivation and rurality on patient-reported outcomes of men living with and beyond prostate cancer diagnosis in the UK: a population-based study

Lesley Smith 1, 2, Amy Downing 2, 3 , Paul Norman ${ }^{4}$, Penny Wright ${ }^{3}$, Luke Hounsome ${ }^{5}$, Eila Watson ${ }^{6}$, Richard Wagland ${ }^{7}$, Peter Selby ${ }^{3,8}$, Paul Kind ${ }^{9}$, David W Donnelly ${ }^{10}$, Hugh Butcher ${ }^{3}$, Dyfed Huws ${ }^{11}$, Emma McNair ${ }^{12}$, Anna Gavin ${ }^{10,}{ }^{*}$, Adam W Glaser 2, 3, 8 *

* Joint senior author

\section{Affiliations}

1. Leeds Institute of Cardiovascular and Metabolic Medicine, University of Leeds, Leeds UK

2. Leeds Institute of Data Analytics, University of Leeds, Leeds, UK

3. Leeds Institute of Medical Research at St James's, University of Leeds, Leeds, UK

4. School of Geography, University of Leeds, Leeds, UK

5. National Cancer Registration and Analysis Service, Public Health England, Bristol, UK

6. Department of Midwifery, Community and Public Health, School of Nursing and Midwifery, Oxford Brookes University, Oxford, UK

7. Faculty of Health Sciences, University of Southampton, Southampton, UK

8. Leeds Teaching Hospitals NHS Trust, Leeds, UK

9. Academic Unit of Health Economics, University of Leeds, Leeds, UK

10. Northern Ireland Cancer Registry, Centre for Public Health, Queen's University Belfast, Belfast

11. Welsh Cancer Intelligence and Surveillance Unit, Public Health Wales, Cardiff, UK

12. Information Services Division, NHS National Services Scotland, Edinburgh, UK

\section{Corresponding author}

Lesley Smith, L.F.Smith@leeds.ac.uk

LIDA, Level 11, Worsley Building, Clarendon Way, University of Leeds, UK, LS9 2JT

Key words: Prostate cancer, deprivation, rurality, inequalities, health-related quality of life, functional outcomes

Word Count: 2998 


\section{Highlights}

- National study exploring the impact of deprivation and rurality on self-reported healthrelated quality of life (HRQL) following prostate cancer

- The impact of deprivation and rurality on HRQL was not greater than would be expected in the general population

- Some functional prostate specific outcomes were affected by deprivation

- No clinically meaningful differences in HRQL were identified by rurality of residence

\section{List of abbreviations}

ADT: androgen deprivation therapy; AS: active surveillance; EPIC: Expanded Prostate Cancer Index Composite; HRQL: health related quality of life; HSE: Health Survey for England; IMD: Index of Multiple Deprivation; LAPCD: Life After Prostate Cancer Diagnosis; LSOA: Lower Super Output Area; NHS: National Health Service; NI: Northern Ireland; ONS: Office for National Statistics; pph: persons per hectare; PSA: Prostate Specific Antigen; SAH: self-assessed health; UAG: User Advisory Group; UK: United Kingdom 


\section{Abstract}

\section{Background}

In the UK, inequalities exist in prostate cancer incidence, survival and treatment by area deprivation and rurality. This work aimed to identify variation in patient-reported outcomes of men with prostate cancer by area type.

\section{Methods}

A population-based survey of men 18-42 months after prostate cancer diagnosis $(\mathrm{N}=35608)$ measured self-assessed health (SAH) using the EQ-5D and five functional domains using the Expanded Prostate Cancer Index Composite (EPIC-26).

\section{Results}

Mean SAH was higher for men in least deprived areas compared to most deprived (difference $6.3(95 \% \mathrm{Cl} 5.6$ to 7.2$))$. SAH scores were lower for men in most urban areas compared to most rural (difference $2.4(95 \% \mathrm{Cl} 1.8$ to 3.0$)$ ). Equivalent estimates in the general population reported a 13 point difference by deprivation and a 4 point difference by rurality. For each EPIC-26 domain, functional outcomes were better for men in the least deprived areas, with clinically meaningful differences observed for urinary incontinence and hormonal function. There were no clinically meaningful differences in EPIC-26 outcomes by rurality with less than a three point difference in scores for each domain between urban and rural areas.

\section{Conclusion}

In men 18-42 months post diagnosis of prostate cancer in the UK, impacts of area deprivation and rurality on self-assessed health related quality of life were not greater than would be expected in the general population. However, clinically meaningful differences were identified for some prostate functional outcomes (urinary and hormonal function) by deprivation. No impact by rurality of residence was identified. 


\section{Introduction}

Socioeconomic deprivation and rurality are associated with variations in health outcomes. In the United Kingdom (UK), for general health conditions, all-cause mortality and life expectancy outcomes are more favourable in less deprived areas [1-3]. "Rurality of residence" is a complicated concept evaluating urban versus rural habitation classified by higher to lower population densities and by less to more greenspace [4]. Variations in health by rurality are known to occur: in the main, illness and mortality levels increase with higher levels of urbanisation [5, 6]. However, a U-shape in illness and mortality levels, with better health in suburban and semi-rural areas compared with urban and far rural areas, is known to exist. It is postulated that the latter relates to distances to health and support services [7]. Generally urban areas tend to be more deprived and rural areas less deprived but for each measure there is sufficient variation to investigation health outcomes by both of these area types [8].

In the UK, as for the majority of the developed world, prostate cancer survival has increased substantially over the last 40 years [9] with a current predicted 10-year net survival of $78 \%$ [10]. Socioeconomic gradients in prostate cancer survival have been demonstrated with lower incidence and survival for men living in more deprived areas [11-14]. However, the deprivation gap in survival has narrowed over time [15]. For men diagnosed in 2010 in England there were no differences in 1-year survival by deprivation [16]. Analysis by rurality of residence shows greater heterogeneity, reviews of international studies have suggested lower incidence and survival rates in more rural areas [17-19]. However, in England prostate cancer incidence is higher is rural areas [20]. Additionally, deprivation and rurality have been shown to impact on uptake of Prostate Specific Antigen (PSA) testing, stage of presentation and types of treatment received $[18,21,22]$. Men from more deprived areas have lower rates of PSA testing and more advanced stage of disease at presentation as do men living in rural areas $[18,21]$. In the UK men from more deprived areas were less likely to be treated with surgery or radiotherapy, after adjustment for case-mix including stage [21, 22].

Treatment for prostate cancer may impact physically, psychologically and socially, affecting overall health-related quality of life (HRQL). Declines in urinary, bowel and sexual function following prostate cancer treatment have been reported [23-25]. The UK population-based Life After Prostate Cancer Diagnosis (LAPCD) study has reported HRQL and functional outcomes for men with prostate cancer 18-42 months post diagnosis [26]. HRQL was 
generally high, with the exception of sexual function, and similar to men in the general population. In addition, regional variations in self-reported outcomes remained after adjustment for patient case-mix, including deprivation [27].

In order to sustain the well-being of the ever increasing number of cancer survivors, large unselected studies of HRQL and functional outcomes are needed to identify problems in potentially disadvantaged groups. To date, it is not known if there are differences in the HRQL of men living with and beyond prostate cancer diagnosis by deprivation and rurality. This population-based study examines the associations between area of residence (based on both deprivation and rurality) and self-reported outcomes in men with prostate cancer in the UK.

\section{Materials and Methods}

\subsection{Study population}

The Life After Prostate Cancer Diagnosis (LAPCD) study methodology has been described in detail elsewhere $[26,28]$. Briefly a cross-sectional postal survey of men diagnosed with prostate cancer in the previous 18-42 months in the UK was conducted. Men with prostate cancer were identified from national cancer registries in England, Wales and Northern Ireland (NI) and through cancer registry verified hospital activity data in Scotland. In England, all NHS Trusts were approached and 111 participated (21 declined and 4 were excluded as they were involved in similar studies). All providers in Wales, Scotland and $\mathrm{NI}$ participated. Overall, $82 \%$ of eligible men in the UK were invited to participate in the study. Each eligible man was sent a postal survey, via an approved survey provider. Consent was obtained via completion and return of the survey. The postal survey was sent out between October 2015 and November 2016. Details of the response rates have been published previously [26], respondents were more likely to be younger, of white ethnicity, be diagnosed with earlier stage disease and live in less deprived areas.

\subsection{Outcomes}

The survey contained questions to measure HRQL including EQ-5D self-assessed health (SAH) [29] and the Expanded Prostate Cancer Index Composite short form (EPIC-26) [30]. SAH was based on a visual analogue scale ranging from 0 to 100 , where a score of 100 
represents the best possible health. EPIC-26 measures functional outcomes across five domains (urinary incontinence, urinary irritation and obstruction, bowel, sexual and hormonal function) using 26 items. Summary scores for each domain were calculated ranging from 0 to 100 , with 100 representing best possible function.

\subsection{Deprivation and rurality}

Deprivation and rurality measures were assigned based on postcode of residence at time of diagnosis. Within the UK, the various Indexes of Multiple Deprivation are country specific so, to ensure consistency, we calculated UK-wide deprivation based on the Townsend Index $[31,32]$. Townsend scores and population weighted quintiles were calculated for each UK Lower Super Output Area (LSOA) in England and Wales, Datazone in Scotland and Super Output Area in NI using four census variables (unemployment, non-car ownership, nonhome ownership and household overcrowding). Population density was calculated for each small area in the UK based on person per hectare (pph) from the 2011 census. The areas were then ranked according to population density and split into fifths, to define five categories with decreasing rurality as follows: 1 most urban, 33-681 pph; 2 very urban, 26-33 pph; 3 urban, 13-26 pph; 4 rural, 1- 13; 5 very rural, 0.01 - 1 pph.

These deprivation and rurality measures were linked to each respondent in England, Wales and NI. Due to differences with data regulations and access to data in Scotland we were unable to link the same area-based indicators, and therefore different indices for deprivation and rurality were included. The Scottish Index of Multiple Deprivation (SIMD) [33] was used with deprivation scores split into fifths. Rurality was assigned based on the Scottish Government 6-fold Urban-Rural classification which incorporates population size of settlements and accessibility measured by drive time to an urban area [34] (Table A.1).

\subsection{Other variables}

Other socio-demographic and clinical variables were taken from the questionnaire or available from cancer registry data including: age at questionnaire, stage at diagnosis, treatment received and number of other long-term conditions. 


\subsection{Statistical methods}

The association between deprivation, rurality and SAH and each of the five EPIC-26 domains were assessed by log-linear models with robust standard errors to account for the skewed distribution of scores. Results are presented from adjusted models which included age at questionnaire, stage at diagnosis and other long-term conditions.

Initially separate models for each nation were considered due to the lack of consistent deprivation and rurality indicators across the four nations. In addition, the rurality trend by deprivation varied by country (Figure A.1). Initial analyses showed a similar deprivation pattern in England, Wales and NI therefore these three countries were combined in models investigating the association between deprivation and self-reported outcomes. Separate models for Scotland were run using the SIMD. Models for rurality were run separately for each nation.

Further analysis was stratified by treatment including models for those treated with androgen deprivation therapy (ADT) and active surveillance (AS). ADT was of interest as it has previously been shown that men treated with ADT had poorer hormonal and sexual scores than in other treatment groups [26]. As a comparator group, men on AS were chosen as these represent a group of men who have not received treatment for their tumour therefore any reported function problems are not directly related to treatment. For deprivation analysis England, Wales and NI were included in the models stratified by treatment. For rurality analysis stratification by treatment was only conducted for England due to small numbers in the other nations (when breaking down by treatment and rurality groups).

Multiple imputation was used to account for missing data for all outcomes, sociodemographic and clinical variables [35, 36]. No imputations were made for missing geographic indicators. Multiple imputation using chained equations was conducted separately for each country and accounted for all outcomes, deprivation, rurality, age, stage, treatment, long-term conditions and geographic indicators (Cancer Alliances for England, Local Authority Districts in Wales, Local Government Districts in NI and Health Boards in Scotland). Twenty imputations were run, and the results combined by Rubin's rule. The results presented in this paper are from the imputed models. 
From the regression models adjusted means scores (based on geometric means) and 95\% confidence intervals were calculated for each deprivation and rurality category, assuming the country specific distribution of the other covariables in the model. The large sample size included in this study means that statistical significance of results may be evident with only small differences in mean scores which may not be clinically relevant. Minimally important differences in scores have been previously published [37, 38] and these have been used alongside the predicted estimates when interpreting the results (Table A.2). For example, for SAH a 7-point difference between groups is considered clinically meaningful while for the sexual function domain of EPIC a difference of 10-12 points is considered clinically important.

EQ-5D SAH was collected in the 2012 Health Survey for England [39]. Mean SAH scores for men aged 60+ completing this survey by area level deprivation (using IMD 2010 [40]) and rurality (using 2011 ONS Urban-Rural classification [41]) were calculated to provide comparator scores in the general population.

\section{Results}

A total of 35823 men responded to the survey (60.8\%). For this study, 215 were excluded from analysis due to missing geographic information (78 from England, 13 from Wales and 124 from Scotland), resulting in a final sample of 35608 men: 30387 in England, 2507 in Wales, 1019 in NI and 1695 in Scotland. Clinical details of the study population are provided in Table 1. Overall, 38\% of men were treated with ADT and $8 \%$ on AS (Tables 1, A.2, A.3).

In England 32\% of men lived in the least deprived areas compared to $26 \%$ in Wales, $14 \%$ in $\mathrm{NI}$ and $28 \%$ in Scotland, while 9\% of men in England, 4\% of men in Wales, $7 \%$ of men in $\mathrm{NI}$ and $13 \%$ of men in Scotland lived in the most deprived areas. In England $46 \%$ of men lived in the most urban areas compared to $20 \%$ in Wales, $21 \%$ in $\mathrm{NI}$ and $37 \%$ of men in Scotland lived in Large Urban Areas (Table 2). Compared to the general population of all men aged $60+$ within each country the study sample included more men in the least deprived areas and fewer men in the most deprived areas (Table 2). 


\subsection{Association between deprivation and HRQL}

Within each country, mean SAH scores were highest for men living in the least deprived areas compared to those living in the most deprived with differences ranging from 4 points in Wales to 12 points in NI (Table 3). Equivalent estimates from the general population showed a 13 point difference. For England, Wales and $\mathrm{NI}$ combined, the mean difference in adjusted SAH scores was 6.3 points (95\% CI 5.6-7.2) overall, 5.4 points (4.1-6.8) for men treated with ADT and 7.3 points (4.3-10.3) for men on AS (Table 4).

There were differences in mean scores for each EPIC-26 domain by deprivation. In England, Wales and $\mathrm{NI}$ combined, the adjusted mean scores were highest (signifying better function) in men living in the least deprived areas and lowest for those in most deprived (Figure 1, Table A.5), with clinically meaningful differences in urinary incontinence and hormonal function. For sexual function analysed by type of treatment, the difference between the least and most deprived men treated with ADT was 1.9 points versus 7.4 points for men on AS (Figure1). However, neither of these differences reached the threshold for a minimally important clinical difference.

\subsection{Association between rurality and HRQL}

In England, mean SAH was 75.9 (75.6-76.2) for men living in the most urban areas and 78.3 (77.7-78.8) for men in the most rural areas. Within the other countries there was no clear pattern in outcomes by rurality (Table 5). In England, the mean difference in adjusted scores was 2.4 points (1.8-3.0) higher for men in rural areas compared to urban areas, a similar difference was found when stratifying by treatment (mean difference 2.4 (1.3-3.4) for ADT and mean difference 2.7 (0.8-4.7) for AS) (Table 4). Equivalent estimates from the general population showed a 4 point difference in mean SAH between men from urban and rural areas (Table 5).

In England the EPIC-26 scores for each domain were generally higher for those living in the most rural areas compared to the most urban, but differences were small (less than a 3 point difference for all domains) (Figure 2, Table A.6). Stratification by treatment showed similar differences between the most urban and most rural for ADT and AS except for sexual function where the difference between most urban and most rural areas was -1.6 points for men treated with ADT compared to -5.7 points for men on AS (Figure 2). However, this difference was not clinically meaningful. 


\section{Discussion}

To the best of our knowledge, this is the largest whole population-based report on the impact of deprivation on the quality of survival of men diagnosed with prostate cancer and the first to explore the impact of rurality of residence for any of the common cancer sites. The impact of increasing deprivation on overall self-reported HRQL appears to be less marked, and definitively no greater, than in the general population. Urinary and hormonal function domains were impacted by deprivation with no effects reported in sexual and bowel function. Rurality of residence had no meaningful impact on self-reported overall HRQL and functional outcomes.

The differences in SAH reported by men with prostate cancer in the least and most deprived areas (6 point difference) was no greater than that reported by men in the general population (13 point difference). The absence of a deleterious effect of deprivation is reassuring but perhaps surprising because of the evidence for some functional differences. One possible explanation for this may be the "gap hypothesis", originally proposed by Calman, whereby quality of life measures the gap, at a particular period of time between an individual's hopes and expectations and their present experiences [42]. An individual's aims and goals may be modified by cancer diagnosis and treatment and quality of life may improve due to a reduction in expectations and satisfaction with what they have, so that they report relatively high HRQL $[42,43]$. Without baseline measures of SAH within the LAPCD cohort we cannot assess any individual level changes in HRQL, however it may be that this "gap hypothesis" operates differentially between men living in less and more deprived areas.

Previous analysis of this cohort has identified that men treated with ADT reported greater problems particularly with hormone-related functioning and sexual health [26]. The trends in deprivation, rurality and outcomes for men receiving ADT were similar to the full cohort. However, a stronger deprivation gradient and rurality gradient were observed for men on active surveillance, particularly for sexual function. Differences in sexual function scores of 7 points by deprivation and 6 points by rurality were observed, but these differences were not thought to be clinically meaningful. However, it should be noted that the overall mean sexual scores for men on AS were substantially higher (i.e. better functioning) than in men treated with ADT for whom there was little variation by deprivation or rurality, with poor sexual function reported by all men regardless of place of residence. 
Whilst the sample size is large, there is a potential responder bias within the study. Compared to all men diagnosed with prostate cancer during the same time period, respondents were more likely to be younger, of white ethnicity, be diagnosed with earlier staged disease and live in less deprived areas [26]. Despite participants completing validated internationally recommended outcome measures [44], no equivalent UK wide baseline population data are available for prostate specific outcomes. To compensate for this, men managed with AS (who received no treatment) have been used as a comparator. For the EQ-5D HRQL assessment, normative data from the Health Survey for England [39] was used, thereby identifying that the men living with and beyond prostate cancer diagnosis did not self-report worse HRQL than the general population and the effects of increasing deprivation were similar. Further work examining inequalities of other outcomes such as psychological wellbeing and social support, which are not included in this study are needed.

Our measure of rurality is based on population density, whist this is not strictly an urban-rural measure it is a good proxy and there are no alternative consistently adopted UK-wide urbanrural measures. Two smaller scale studies in Ireland have investigated urban-rural inequalities in quality of life in survivors of breast cancer [45] and head and neck cancer [46]. These studies used a composite measure of urban-rural classification based on population density, settlement size and proximity to treatment hospital. However defined, rurality measures a complex series of interactions between social, environmental and behavioural processes. We were unable to account for travel time or distance to treatment centre as this data was not available. These factors are known to impact on types of treatment used in prostate cancer.

Other measures of area level deprivation are commonly used including country specific Indexes of Multiple Deprivation [33, 40,47,48] which are composite scores derived from a number of indicators covering different domains including: income, employment, education, skills and training, health and disability, crime, housing and living environment. IMD includes a larger range of domains, and uses data from local government and other agencies and is not only based on census data like Townsend, which focusses on four indicators of material deprivation (unemployment, non-car ownership, non-home ownership and household overcrowding). However, the Townsend measure was used in this study as it can be calculated consistently across the all countries in the UK, although it was not possible to use this measure in Scotland (due to data access issues). The implications of using a different 
measure in Scotland cannot currently be determined but correlations of 0.85 between Townsend and the Scottish IMD and 0.51 between the density based and Scottish scheme suggest results would be similar whichever measures were used.

In this study, we have examined associations with deprivation and rurality independently; however, there is a strong correlation between the two measures with a tendency for urban areas to be more deprived and rural areas less deprived but sufficient variation to justify investigation of both of these area typologies [8]. Many factors such as differences in quality and access to primary care, differences in health seeking behaviours and distances and willingness to travel to hospitals for treatment may explain why differences persist between deprivation and rurality groups.

In conclusion, it is reassuring to have identified little impact of deprivation and rurality of residence on self-assessed health-related quality of life and prostate functional outcomes (bladder, bowel, sexual) 18-42 months post diagnosis of prostate cancer across the UK. However, further targeted work is needed to establish whether this finding holds for hard to reach population groups known to be at increased risk of poor health access such as Black and Minority Ethnic groups and those with restricted geographic mobility such as those with limited access to transport. Additionally, as cancer survival and prevalence increase, to support elimination of health inequalities it is recommended that the impact of rurality of residence and deprivation on quality of outcomes from other cancer types be evaluated. 


\section{Acknowledgments}

We thank all the men who completed surveys. We acknowledge the following people and groups for their contribution to the development and running of the study: Rebecca Mottram, Majorie Allen, Therese Kearney, Oonagh McSorley, Heather Kinnear, Victoria Cairnduff, Linda Roberts, Conan Donnelly, Fraser Munro, Dawn Allen, Janet Warlow, the User Advisory Group, the Clinical and Scientific Advisory Group, and Picker Institute Europe (Oxford, UK). This study is based in part on information collected and quality assured by the cancer registries in each nation. Their work uses data provided by patients and collected by health services as part of their care and support.

\section{Authors' contributions}

AG and AWG are co-Principal Investigators and designed the Life After Prostate Cancer Diagnosis study together with co-investigators AD, PW, LH, PS, EW, RW, PK and HB. PS is chair of the Clinical and Scientific Advisory Group and HB is chair of the User Advisory Group. AWG, AD, PN and LS conceived and designed the study. LS and PN carried out the statistical analysis. DD, EM and DH advised on study design, data collection and interpretation of data from the devolved nations. LS, AD, PN and AWG wrote the initial draft of the paper. All authors contributed to critically revising the paper and approved the final version.

\section{Funding}

The Life after Prostate Cancer Diagnosis study was funded by the Movember Foundation, in partnership with Prostate Cancer UK, as part of the Prostate Cancer Outcomes programme, grant number BO26/Mo. The funders had no role in the study design, data collection, analysis and interpretation of results, or writing of the manuscript.

\section{Competing interests}

All authors declare they have no conflicts of interest

\section{Ethical approval}

The study received the following approvals: Newcastle \& North Tyneside 1 Research Ethics Committee (15/NE/0036), Confidentiality Advisory Group (15/CAG/0110), NHS Scotland 
Public Benefit and Privacy Panel (0516-0364), Office of Research Ethics Northern Ireland (16/NI/0073) and NHS R\&D approval from Wales, Scotland and Northern Ireland.

\section{Data availability}

Consent for data sharing outside the research team was not sought from survey respondents. 


\section{References}

[1] S. Macintyre, Geographical inequalities in mortality, morbidity and health-related behaviour in England, Inequalities in health: The evidence presented to the independent inquiry into inequalities in health, Chaired by Sir Donald Acheson, Policy Press Bristol, 1999, pp. 148-154.

[2] E.K. Dearden, C.D. Lloyd, G. Catney, A spatial analysis of health status in Britain, 1991-2011, Soc Sci Med 220 (2019) 340-352.

[3] R. Seaman, T. Riffe, A.H. Leyland, F. Popham, A. van Raalte, The increasing lifespan variation gradient by area-level deprivation: A decomposition analysis of Scotland 1981-2011, Social Science \& Medicine 230 (2019) 147-157.

[4] R. Allan, P. Williamson, H. Kulu, Unravelling urban-rural health disparities in England, Popul Space Place 23(8) (2017).

[5] L. Kyte, C. Wells, Variations in life expectancy between rural and urban areas of England, 200107, Health Stat Q (46) (2010) 25-50.

[6] M. Riva, S. Curtis, P. Norman, Residential mobility within England and urban-rural inequalities in mortality, Social Science \& Medicine 73(12) (2011) 1698-1706.

[7] S. Barnett, P. Roderick, D. Martin, I. Diamond, A multilevel analysis of the effects of rurality and social deprivation on premature limiting long term illness, J Epidemiol Community Health 55(1) (2001) 44-51.

[8] A. Gartner, D. Farewell, P. Roach, F. Dunstan, Rural/urban mortality differences in England and Wales and the effect of deprivation adjustment, Soc Sci Med 72(10) (2011) 1685-94.

[9] Cancer Research UK, Prostate Cancer Survival Statistics. https://www.cancerresearchuk.org/health-professional/cancer-statistics/statistics-by-cancertype/prostate-cancer/survival, 2020. (Accessed 17th Aug 2020.

[10] Office for National Statistics, Cancer survival in England: adult, stage at diagnosis and childhood - patients followed up to 2018.

https://www.ons.gov.uk/peoplepopulationandcommunity/healthandsocialcare/conditionsanddiseas es/bulletins/cancersurvivalinengland/stageatdiagnosisandchildhoodpatientsfollowedupto2018\#10year-predicted-survival-estimates, 2019. (Accessed 20th April 2020.

[11] S. Rowan, B. Rachet, D.M. Alexe, N. Cooper, M.P. Coleman, Survival from prostate cancer in England and Wales up to 2001, Br J Cancer 99 Suppl 1 (2008) S75-7.

[12] L.G. Shack, B. Rachet, D.H. Brewster, M.P. Coleman, Socioeconomic inequalities in cancer survival in Scotland 1986-2000, Br J Cancer 97(7) (2007) 999-1004.

[13] K. Shafique, D.S. Morrison, Socio-economic inequalities in survival of patients with prostate cancer: role of age and Gleason grade at diagnosis, PLoS One 8(2) (2013) e56184.

[14] J. Klein, O. von dem Knesebeck, Socioeconomic inequalities in prostate cancer survival: A review of the evidence and explanatory factors, Soc Sci Med 142 (2015) 9-18.

[15] A. Exarchakou, B. Rachet, A. Belot, C. Maringe, M.P. Coleman, Impact of national cancer policies on cancer survival trends and socioeconomic inequalities in England, 1996-2013: population based study, BMJ 360 (2018) k764.

[16] National Cancer Intelligence Network, Cancer and equality groups: key metrics. 2015 report, 2015.

[17] N. Afshar, D.R. English, R.L. Milne, Rural-urban residence and cancer survival in high-income countries: A systematic review, Cancer (2019).

[18] P. Dasgupta, P.D. Baade, J.F. Aitken, N. Ralph, S.K. Chambers, J. Dunn, Geographical Variations in Prostate Cancer Outcomes: A Systematic Review of International Evidence, Front Oncol 9 (2019) 238. [19] Z. Obertova, C. Brown, M. Holmes, R. Lawrenson, Prostate cancer incidence and mortality in rural men - a systematic review of the literature, Rural and Remote Health 12(2) (2012).

[20] N.C.I. Network, NCIN Data Briefing. The effect of rurality on cancer incidence and mortality. http://www.ncin.org.uk/publications/data briefings/rurality

2011. 
[21] G. Lyratzopoulos, J.M. Barbiere, D.C. Greenberg, K.A. Wright, D.E. Neal, Population based time trends and socioeconomic variation in use of radiotherapy and radical surgery for prostate cancer in a UK region: continuous survey, BMJ 340 (2010) c1928.

[22] M.F. Eylert, A. Bahl, L. Hounsome, J. Verne, E.R. Jefferies, R.A. Persad, The impact of socioeconomic deprivation on incidence, treatment and mortality from prostate cancer in England, 19902010, Journal of Clinical Urology 9(2) (2016) 93-101.

[23] J.L. Donovan, F.C. Hamdy, J.A. Lane, M. Mason, C. Metcalfe, E. Walsh, J.M. Blazeby, T.J. Peters, P. Holding, S. Bonnington, T. Lennon, L. Bradshaw, D. Cooper, P. Herbert, J. Howson, A. Jones, N. Lyons, E. Salter, P. Thompson, S. Tidball, J. Blaikie, C. Gray, P. Bollina, J. Catto, A. Doble, A. Doherty, D. Gillatt, R. Kockelbergh, H. Kynaston, A. Paul, P. Powell, S. Prescott, D.J. Rosario, E. Rowe, M. Davis, E.L. Turner, R.M. Martin, D.E. Neal, T.S.G. Protec, Patient-Reported Outcomes after Monitoring, Surgery, or Radiotherapy for Prostate Cancer, N Engl J Med 375(15) (2016) 1425-1437.

[24] M.J. Resnick, T. Koyama, K.H. Fan, P.C. Albertsen, M. Goodman, A.S. Hamilton, R.M. Hoffman, A.L. Potosky, J.L. Stanford, A.M. Stroup, R.L. Van Horn, D.F. Penson, Long-term functional outcomes after treatment for localized prostate cancer, N Engl J Med 368(5) (2013) 436-45.

[25] D.A. Barocas, J. Alvarez, M.J. Resnick, T. Koyama, K.E. Hoffman, M.D. Tyson, R. Conwill, D. McCollum, M.R. Cooperberg, M. Goodman, S. Greenfield, A.S. Hamilton, M. Hashibe, S.H. Kaplan, L.E. Paddock, A.M. Stroup, X.C. Wu, D.F. Penson, Association Between Radiation Therapy, Surgery, or Observation for Localized Prostate Cancer and Patient-Reported Outcomes After 3 Years, JAMA 317(11) (2017) 1126-1140.

[26] A. Downing, P. Wright, L. Hounsome, P. Selby, S. Wilding, E. Watson, R. Wagland, P. Kind, D.W. Donnelly, H. Butcher, J.W.F. Catto, W. Cross, M. Mason, L. Sharp, D. Weller, G. Velikova, E. McCaughan, R. Mottram, M. Allen, T. Kearney, O. McSorley, D.W. Huws, D.H. Brewster, E. McNair, A. Gavin, A.W. Glaser, Quality of life in men living with advanced and localised prostate cancer in the UK: a population-based study, Lancet Oncol (2019).

[27] D.W. Donnelly, A. Gavin, A. Downing, L. Hounsome, T. Kearney, E. McNair, D. Allan, D.W. Huws, P. Wright, P.J. Selby, P. Kind, E. Watson, R. Wagland, S. Wilding, H. Butcher, R. Mottram, M. Allen, O. McSorley, L. Sharp, M.D. Mason, W.R. Cross, J.W.F. Catto, A.W. Glaser, Regional Variations in Quality of Survival Among Men with Prostate Cancer Across the United Kingdom, European Urology (2019). [28] A. Downing, P. Wright, R. Wagland, E. Watson, T. Kearney, R. Mottram, M. Allen, V. Cairnduff, O. McSorley, H. Butcher, L. Hounsome, C. Donnelly, P. Selby, P. Kind, W. Cross, J.W. Catto, D. Huws, D.H. Brewster, E. McNair, L. Matheson, C. Rivas, J. Nayoan, M. Horton, J. Corner, J. Verne, A. Gavin, A.W. Glaser, Life after prostate cancer diagnosis: protocol for a UK-wide patient-reported outcomes study, BMJ Open 6(12) (2016) e013555.

[29] M. Herdman, C. Gudex, A. Lloyd, M. Janssen, P. Kind, D. Parkin, G. Bonsel, X. Badia, Development and preliminary testing of the new five-level version of EQ-5D (EQ-5D-5L), Qual Life Res 20(10) (2011) 1727-36.

[30] J.T. Wei, R.L. Dunn, M.S. Litwin, H.M. Sandler, M.G. Sanda, Development and validation of the expanded prostate cancer index composite (EPIC) for comprehensive assessment of health-related quality of life in men with prostate cancer, Urology 56(6) (2000) 899-905.

[31] P. Norman, , Identifying Change Over Time in Small Area Socio-Economic Deprivation, Applied Spatial Analysis and Policy 3(2) (2010) 107-138.

[32] P. Norman, UK small area characteristics 2011, Mendeley Data, v1. http://dx.doi.org/10.17632/yn47f2yrt2.1, Mendeley 2019.

[33] ISD Scotland, The Scottish Index of Multiple Deprivation (SMID) 2016.

https://www.isdscotland.org/Products-and-Services/GPD-Support/ 2016. (Accessed 20th April 2020.

[34] Scottish Government, Scottish Government Urban Rural Classification.

https://www2.gov.scot/Topics/Statistics/About/Methodology/UrbanRuralClassification. (Accessed

20th April 2020. 
[35] J.A. Sterne, I.R. White, J.B. Carlin, M. Spratt, P. Royston, M.G. Kenward, A.M. Wood, J.R. Carpenter, Multiple imputation for missing data in epidemiological and clinical research: potential and pitfalls, BMJ 338 (2009) b2393.

[36] I.R. White, P. Royston, A.M. Wood, Multiple imputation using chained equations: Issues and guidance for practice, Stat Med 30(4) (2011) 377-99.

[37] A.S. Pickard, M.P. Neary, D. Cella, Estimation of minimally important differences in EQ-5D utility and VAS scores in cancer, Health Qual Life Outcomes 5 (2007) 70.

[38] T.A. Skolarus, R.L. Dunn, M.G. Sanda, P. Chang, T.K. Greenfield, M.S. Litwin, J.T. Wei, P. Consortium, Minimally important difference for the Expanded Prostate Cancer Index Composite Short Form, Urology 85(1) (2015) 101-5.

[39] NHS Digital, Health Survey for England - 2012. https://digital.nhs.uk/data-andinformation/publications/statistical/health-survey-for-england/health-survey-for-england-2012, 2013.

[40] Ministry of Housing Communities and Local Government, English indices of deprivation 2010. https://www.gov.uk/government/statistics/english-indices-of-deprivation-2010, 2011. (Accessed 20th April 2020.

[41] Office for National Statistics, 2011 rural/urban classification. https://www.ons.gov.uk/methodology/geography/geographicalproducts/ruralurbanclassifications/2 011ruralurbanclassification. (Accessed 20th April 2020.

[42] K.C. Calman, Quality of life in cancer patients--an hypothesis, J Med Ethics 10(3) (1984) 124-7. [43] A.W. Glaser, Resilience of men and the gap hypothesis of quality of life: Health utility outcome measurement in prostate cancer, Eur Urol (2019).

[44] N.E. Martin, L. Massey, C. Stowell, C. Bangma, A. Briganti, A. Bill-Axelson, M. Blute, J. Catto, R.C. Chen, A.V. D'Amico, G. Feick, J.M. Fitzpatrick, S.J. Frank, M. Froehner, M. Frydenberg, A. Glaser, M. Graefen, D. Hamstra, A. Kibel, N. Mendenhall, K. Moretti, J. Ramon, I. Roos, H. Sandler, F.J. Sullivan, D. Swanson, A. Tewari, A. Vickers, T. Wiegel, H. Huland, Defining a standard set of patient-centered outcomes for men with localized prostate cancer, Eur Urol 67(3) (2015) 460-7.

[45] C. Cahir, A.A. Thomas, S.U. Dombrowski, K. Bennett, L. Sharp, Urban-Rural Variations in Qualityof-Life in Breast Cancer Survivors Prescribed Endocrine Therapy, Int J Environ Res Public Health 14(4) (2017).

[46] A.A. Thomas, A. Timmons, M. Molcho, A. Pearce, P. Gallagher, P. Butow, E. O'Sullivan, R. Gooberman-Hill, C. O'Neill, L. Sharp, Quality of life in urban and rural settings: a study of head and neck cancer survivors, Oral Oncol 50(7) (2014) 676-82.

[47] Northern Ireland Statistics and Research Agency, NI multiple deprivation measure. https://www.nisra.gov.uk/statistics/deprivation. (Accessed 20th April 2020.

[48] Welsh Government, Welsh Index of Multiple Deprivation.

https://statswales.gov.wales/Catalogue/Community-Safety-and-Social-Inclusion/Welsh-Index-ofMultiple-Deprivation, 2019. (Accessed 20th April 2020. 
Table 1: Characteristics of LAPCD cohort by country, values are $n(\%)$ unless otherwise stated

\begin{tabular}{lcccc}
\hline & $\begin{array}{c}\text { England } \\
\mathbf{N}=\mathbf{3 0 3 8 7}\end{array}$ & $\begin{array}{c}\text { Wales } \\
\mathbf{N = 2 5 0 7}\end{array}$ & $\begin{array}{c}\text { Northern } \\
\text { Ireland } \\
\mathbf{N}=\mathbf{1 0 1 9}\end{array}$ & $\begin{array}{c}\text { Scotland } \\
\mathbf{N}=\mathbf{1 6 9 5}\end{array}$ \\
\hline $\begin{array}{l}\text { Age, mean(SD) } \\
\text { Treatment }\end{array}$ & $71.7(8.0)$ & $71.5(7.9)$ & $70.1(8.2)$ & $70.8(7.4)$ \\
Active surveillance & $2480(8.2)$ & $243(9.7)$ & $90(8.8)$ & $95(5.6)$ \\
Surgery alone & $6134(20.2)$ & $448(17.9)$ & $9(9.2)$ & $347(20.5)$ \\
EBRT alone & $2051(6.7)$ & $236(9.4)$ & $132(13.0)$ & $106(6.3)$ \\
Brachytherapy alone & $998(3.3)$ & $46(1.8)$ & $62(6.1)$ & $93(5.5)$ \\
ADT alone & $2723(9.0)$ & $166(6.6)$ & $62(6.1)$ & $146(8.6)$ \\
Watchful waiting & $1975(6.5)$ & $171(6.8)$ & $61(6.0)$ & $76(4.5)$ \\
EBRT \& ADT & $6242(20.5)$ & $609(24.3)$ & $258(25.3)$ & $335(19.8)$ \\
Surgery \& EBRT/ADT & $2046(6.7)$ & $147(5.9)$ & $44(4.3)$ & $97(5.7)$ \\
Systemic \& ADT & $515(1.7)$ & $49(2.0)$ & $16(1.6)$ & $45(2.7)$ \\
Systemic \& EBRT & $430(1.4)$ & $34(1.4)$ & $16(1.6)$ & $30(1.8)$ \\
Missing & $4793(15.8)$ & $358(14.3)$ & $184(18.1)$ & $325(19.2)$ \\
Stage & & & & \\
I/II & $16,768(55.2)$ & $1,446(57.7)$ & $617(60.5)$ & $719(42.4)$ \\
III & $6,178(20.3)$ & $403(16.1)$ & $226(22.2)$ & $384(22.7)$ \\
IV & $3,226(10.6)$ & $233(9.3)$ & $126(12.4)$ & $330(19.5)$ \\
Missing & $4,215(13.9)$ & $425(17.0)$ & $50(4.9)$ & $262(15.5)$ \\
Number of long-term conditions & & & & \\
0 & $8,881(29.2)$ & $684(27.3)$ & $294(28.9)$ & $475(28.0)$ \\
1 & $10,606(34.9)$ & $873(34.8)$ & $362(35.5)$ & $609(35.9)$ \\
2 & $6,020(19.8)$ & $544(21.7)$ & $204(20.0)$ & $350(20.6)$ \\
3 & $2,656(8.7)$ & $245(9.8)$ & $95(9.3)$ & $155(9.1)$ \\
$4+$ & $2224(7.3)$ & $161(6.4)$ & $64(6.3)$ & $106(6.3)$ \\
\hline
\end{tabular}

Systemic therapy includes chemotherapy, abiraterone, and enzalutamide

$\mathrm{ADT}=$ Androgen deprivation therapy, EBRT $=$ external beam radiotherapy, $\mathrm{LAPCD}=\mathrm{Life}$ After Prostate Cancer Diagnosis 
Table 2: Distribution of geographic indicators by country, LAPCD cohort and the general population*

\begin{tabular}{|c|c|c|c|c|c|c|c|c|c|}
\hline \multirow[b]{2}{*}{$\begin{array}{l}\text { Townsend } \\
\text { Deprivation }\end{array}$} & \multicolumn{2}{|c|}{ England } & \multicolumn{2}{|c|}{ Wales } & \multicolumn{2}{|c|}{ Northern Ireland } & \multicolumn{3}{|c|}{ Scotland } \\
\hline & $\begin{array}{c}\text { LAPCD } \\
\mathrm{N}=30387 \\
\text { n (\%) }\end{array}$ & $\begin{array}{c}\text { General } \\
\text { population } \\
60+\text { years } \\
(\%)\end{array}$ & $\begin{array}{c}\text { LAPCD } \\
\mathrm{N}=2507 \\
\mathrm{n}(\%)\end{array}$ & $\begin{array}{c}\text { General } \\
\text { population } \\
60+\text { years } \\
(\%)\end{array}$ & $\begin{array}{c}\text { LAPCD } \\
\mathrm{N}=1019 \\
\mathrm{n}(\%)\end{array}$ & $\begin{array}{c}\text { General } \\
\text { population } \\
60+\text { years } \\
(\%)\end{array}$ & $\begin{array}{l}\text { Index of multiple } \\
\text { deprivation }\end{array}$ & $\begin{array}{c}\text { LAPCD } \\
\mathrm{N}=1695 \\
\text { n (\%) }\end{array}$ & $\begin{array}{c}\text { General } \\
\text { population } \\
60+\text { years } \\
(\%)\end{array}$ \\
\hline $\begin{array}{l}1 \text { Least } \\
\text { deprived }\end{array}$ & $9617(31.7)$ & $(21.0)$ & $663(26.5)$ & $(19.6)$ & $140(13.7)$ & (11.3) & 1 Least deprived & $469(27.7)$ & $(19.0)$ \\
\hline 2 & $8228(27.1)$ & (20.2) & 708 (28.2) & (24.0) & $253(24.8)$ & (20.1) & 2 & $393(23.2)$ & (19.8) \\
\hline 3 & 5926 (19.5) & (19.2) & $681(27.2)$ & (28.0) & 344 (33.8) & (32.1) & 3 & 364 (21.5) & (22.6) \\
\hline 4 & 3984 (13.1) & (19.6) & 353 (14.1) & (20.4) & $208(20.4)$ & (24.9) & 4 & $253(14.9)$ & (23.3) \\
\hline $\begin{array}{l}5 \text { Most } \\
\text { deprived }\end{array}$ & $2632(8.7)$ & (20.0) & $102(4.1)$ & $(8.0)$ & $74(7.3)$ & (11.7) & 5 Most deprived & $216(12.7)$ & (15.3) \\
\hline Rurality & & & & & & & $\begin{array}{l}\text { Urban/rural } \\
\text { indicator }\end{array}$ & N (\%) & \\
\hline 1 Most urban & $14067(46.3)$ & (52.7) & $505(20.1)$ & $(26.8)$ & $218(21.4)$ & $(22.4)$ & $\begin{array}{l}1 \text { Large Urban } \\
\text { Area }\end{array}$ & $618(36.5)$ & $(29.6)$ \\
\hline 2 Very urban & $2830(9.3)$ & $(8.0)$ & $163(6.5)$ & $(7.0)$ & $64(6.3)$ & (7.1) & $\begin{array}{l}2 \text { Other Urban } \\
\text { Area }\end{array}$ & $469(27.7)$ & $(34.8)$ \\
\hline 3 Urban & $4960(16.3)$ & $(14.4)$ & $401(16.0)$ & $(15.9)$ & $157(15.4)$ & (15.3) & $\begin{array}{l}3 \text { Accessible } \\
\text { Small Town }\end{array}$ & $161(9.5)$ & $(10.1)$ \\
\hline 4 Rural & $5791(19.1)$ & (18.1) & $939(37.5)$ & (33.6) & $303(29.7)$ & (28.3) & $\begin{array}{l}4 \text { Remote Small } \\
\text { Town }\end{array}$ & $63(3.7)$ & $(4.2)$ \\
\hline 5 Very rural & $2739(9.0)$ & $(6.7)$ & 499 (19.9) & $(16.7)$ & $277(27.2)$ & (26.9) & $\begin{array}{l}5 \text { Accessible } \\
\text { Rural }\end{array}$ & $213(12.6)$ & (13.1) \\
\hline & & & & & & & 6 Remote Rural & $171(10.1)$ & $(8.2)$ \\
\hline
\end{tabular}

*General population comparison includes males aged $60+$ years only

LAPCD $=$ Life After Prostate Cancer Diagnosis 
Table 3: Adjusted mean self-assessed health (SAH) scores (95\% confidence interval) by deprivation and country, LAPCD cohort and HSE

\begin{tabular}{|c|c|c|c|c|c|c|c|c|c|c|}
\hline \multirow[b]{2}{*}{ Deprivation* } & \multicolumn{2}{|c|}{$\begin{array}{l}\text { England } \\
(\mathrm{N}=30387)\end{array}$} & \multicolumn{2}{|c|}{$\begin{array}{c}\text { Wales } \\
(\mathrm{N}=2507)\end{array}$} & \multicolumn{2}{|c|}{$\begin{array}{l}\text { Northern Ireland } \\
\quad(\mathrm{N}=1019)\end{array}$} & \multicolumn{2}{|c|}{$\begin{array}{l}\text { Scotland } \\
(N=1695)\end{array}$} & \multicolumn{2}{|c|}{$\begin{array}{c}\text { HSE, men } \\
\text { aged 60+ } \\
(\mathrm{N}=1016)\end{array}$} \\
\hline & $\begin{array}{c}\text { Mean } \\
\text { SAH }\end{array}$ & $95 \% \mathrm{Cl}$ & $\begin{array}{c}\text { Mean } \\
\text { SAH }\end{array}$ & $95 \% \mathrm{Cl}$ & $\begin{array}{c}\text { Mean } \\
\text { SAH }\end{array}$ & $95 \% \mathrm{Cl}$ & $\begin{array}{c}\text { Mean } \\
\text { SAH }\end{array}$ & $95 \% \mathrm{Cl}$ & $\begin{array}{c}\text { Mean } \\
\text { SAH }\end{array}$ & (SD) \\
\hline 1 Least deprived & 78.0 & $(77.7,78.3)$ & 75.0 & $(73.9,76.3)$ & 78.2 & $(76.2,80.3)$ & 76.9 & $(75.6,78.3)$ & 79.8 & $(16.1)$ \\
\hline 2 & 77.4 & $(77.1,77.8)$ & 74.1 & $(72.9,75.4)$ & 77.7 & $(75.9,79.5)$ & 75.6 & $(74.0,77.2)$ & 76.3 & $(19.4)$ \\
\hline 3 & 76.6 & $(76.2,77.0)$ & 73.2 & $(71.8,74.6)$ & 74.6 & $(72.8,76.5)$ & 74.0 & $(72.2,75.8)$ & 73.5 & $(18.8)$ \\
\hline 4 & 75.0 & $(74.5,75.6)$ & 71.0 & $(68.9,73.1)$ & 75.5 & $(73.2,77.9)$ & 72.5 & $(70.3,74.8)$ & 68.0 & $(21.7)$ \\
\hline 5 Most deprived & 71.7 & $(70.9,72.4)$ & 70.6 & $(67.3,74.1)$ & 66.6 & $(61.6,71.9)$ & 70.0 & $(67.3,72.7)$ & 66.7 & $(21.4)$ \\
\hline
\end{tabular}

Adjusted for age, stage at diagnosis and long-term conditions

*Townsend used for England, Wales and Northern Ireland, Scottish Index of Multiple Deprivation used in Scotland, English Index of Multiple Deprivation used for HSE

$\mathrm{Cl}=$ Confidence interval, HSE= Health Survey for England, LAPCD= Life After Prostate Cancer Diagnosis, SAH = Self-assessed Health, SD = Standard Deviation 
Table 4: Self-assessed health (SAH) adjusted mean scores and difference in mean scores (95\% confidence interval) overall and stratified by treatment, LAPCD cohort

\begin{tabular}{|c|c|c|c|c|c|c|c|c|c|}
\hline & \multicolumn{3}{|c|}{ All LAPCD study } & \multicolumn{3}{|c|}{$\begin{array}{c}\text { Androgen deprivation therapy } \\
\text { only }\end{array}$} & \multicolumn{3}{|c|}{ Active surveillance only } \\
\hline & Mean SAH & Difference & $95 \% \mathrm{Cl}$ & $\begin{array}{c}\text { Mean } \\
\text { SAH }\end{array}$ & Difference & $95 \% \mathrm{Cl}$ & $\begin{array}{c}\text { Mean } \\
\text { SAH }\end{array}$ & Difference & $95 \% \mathrm{Cl}$ \\
\hline $\begin{array}{l}\text { Deprivation } \\
\text { (England, Wales } \\
\text { and } \mathrm{NI} \text { ) }\end{array}$ & $N=33913$ & & & $N=12877$ & & & $N=2813$ & & \\
\hline 1 Least deprived & 77.8 & ref & - & 75.4 & ref & - & 80.5 & ref & - \\
\hline 2 & 77.2 & 0.7 & $(0.2,1.1)$ & 75.1 & 0.3 & $(-0.4,1.0)$ & 79.7 & 0.8 & $(-0.4,2.1)$ \\
\hline 3 & 76.2 & 1.7 & $(1.2,2.1)$ & 73.9 & 1.5 & $(0.6,2.3)$ & 80.2 & 0.4 & $(-1.1,-1.9)$ \\
\hline 4 & 74.7 & 3.1 & $(2.5,3.7)$ & 72.5 & 2.8 & $(1.8,3.9)$ & 77.5 & 3 & $(1.1,5.0)$ \\
\hline 5 Most deprived & 71.5 & 6.3 & $(5.6,7.2)$ & 70.0 & 5.4 & $(4.1,6.8)$ & 73.3 & 7.3 & $(4.3,10.3)$ \\
\hline $\begin{array}{l}\text { Rurality } \\
\text { (England only) }\end{array}$ & $N=30387$ & & & $N=11526$ & & & $N=2480$ & & \\
\hline Most urban & 75.9 & ref & - & 73.9 & ref & - & 78.8 & ref & - \\
\hline Very urban & 76.3 & -0.5 & $(-1.2,0.2)$ & 73.9 & 0.04 & $(-1.1,1.1)$ & 79.9 & -1.1 & $(-3.1,0.8)$ \\
\hline Urban & 77.0 & -1.2 & $(-1.7,-0.6)$ & 74.9 & -1 & $(-1.9,-0.1)$ & 80.4 & -1.6 & $(-3.3,-0.03)$ \\
\hline Rural & 77.5 & -1.6 & $(-2.1,-1.2)$ & 74.9 & -1 & $(-1.8,-0.2)$ & 79.7 & -0.9 & $(-2.4,0.6)$ \\
\hline Very rural & 78.3 & -2.4 & $(-3.0,-1.8)$ & 76.3 & -2.4 & $(-3.4,-1.3)$ & 81.5 & -2.7 & $(-4.7,-0.8)$ \\
\hline
\end{tabular}

Deprivation models include men in England, Wales and Northern Ireland, Rurality models include men in England only

Adjusted for age, stage at diagnosis and long-term conditions

$\mathrm{Cl}=$ Confidence interval, LAPCD $=$ Life After Prostate Cancer Diagnosis, $\mathrm{NI}=$ Northern Ireland, SAH $=$ Self-assessed Health, 
Table 5: Adjusted mean self-assessed health (SAH) scores (95\% confidence interval) by rurality and country, LAPCD cohort and HSE

\begin{tabular}{|c|c|c|c|c|c|c|c|c|c|c|}
\hline \multirow[b]{2}{*}{ Rurality } & \multicolumn{2}{|c|}{$\begin{array}{l}\text { England } \\
(\mathrm{N}=30387)\end{array}$} & \multicolumn{2}{|c|}{$\begin{array}{l}\text { Wales } \\
(\mathrm{N}=2507)\end{array}$} & \multicolumn{2}{|c|}{$\begin{array}{l}\text { Northern Ireland } \\
(\mathrm{N}=1019)\end{array}$} & \multicolumn{2}{|c|}{$\begin{array}{l}\text { Scotland } \\
(\mathrm{N}=1695)\end{array}$} & \multicolumn{2}{|c|}{$\begin{array}{l}\text { HSE, men } \\
\text { aged } 60+ \\
(\mathrm{N}=1016)\end{array}$} \\
\hline & $\begin{array}{c}\text { Mean } \\
\text { SAH }\end{array}$ & $95 \% \mathrm{Cl}$ & $\begin{array}{c}\text { Mean } \\
\text { SAH }\end{array}$ & $95 \% \mathrm{Cl}$ & $\begin{array}{c}\text { Mean } \\
\text { SAH }\end{array}$ & $95 \% \mathrm{Cl}$ & $\begin{array}{c}\text { Mean } \\
\text { SAH }\end{array}$ & $95 \% \mathrm{Cl}$ & $\begin{array}{c}\text { Mean } \\
\text { SAH }\end{array}$ & (SD) \\
\hline Most urban & 75.9 & $(75.6,76.2)$ & 73.4 & $(71.9,75.0)$ & 73.9 & $(71.5,76.3)$ & & & & \\
\hline Very urban & 76.3 & $(75.8,76.9)$ & 71.6 & $(68.9,74.5)$ & 76.2 & $(72.7,79.8)$ & & & & \\
\hline Urban & 77.0 & $(76.6,77.5)$ & 73.6 & $(71.8,75.4)$ & 75.3 & $(72.7,78.0)$ & & & & \\
\hline Rural & 77.5 & $(77.1,77.9)$ & 74.0 & $(72.9,75.1)$ & 76.3 & $(74.6,78.1)$ & & & & \\
\hline Very rural & 78.3 & $(77.7,78.8)$ & 73.3 & $(71.9,74.8)$ & 75.8 & $(73.8,77.8)$ & & & & \\
\hline \multicolumn{11}{|l|}{ Scottish Urban-Rural } \\
\hline Large Urban area & & & & & & & 73.7 & $(72.4,75.1)$ & & \\
\hline Other urban area & & & & & & & 75.2 & $(73.6,76.7)$ & & \\
\hline Accessible small town & & & & & & & 74.3 & $(71.7,77.0)$ & & \\
\hline Remote small town & & & & & & & 69.2 & $(64.8,74.0)$ & & \\
\hline Accessible rural & & & & & & & 75.2 & $(73.1,77.4)$ & & \\
\hline Remote rural & & & & & & & 76.1 & $(73.8,78.5)$ & & \\
\hline \multicolumn{11}{|c|}{ HSE Rurality of dwelling } \\
\hline Urban & & & & & & & & & 73.0 & $(20.2)$ \\
\hline Town and Fringe & & & & & & & & & 76.4 & (19.0) \\
\hline $\begin{array}{l}\text { Village, hamlet and } \\
\text { isolated dwellings }\end{array}$ & & & & & & & & & 77.4 & (17.2) \\
\hline
\end{tabular}

Rurality of dwelling based on 2011 ONS Urban-Rural classification [41]

$\mathrm{Cl}=$ Confidence interval, LAPCD= Life After Prostate Cancer Diagnosis, SAH = Self-assessed Health, SD = Standard deviation 
Figure 1: Adjusted mean scores for each EPIC-26 domain by deprivation, stratified by treatment, men in England, Wales and Northern Ireland

Footnote: Deprivation group 1 = least deprived, 5 = most deprived

ADT $=$ Androgen Deprivation Therapy, $A S=$ Active Surveillance

Figure 2: Adjusted mean scores for each EPIC-26 domain by rurality fifth, stratified by treatment, men in England only

Footnote: Rurality group 1 = Most Urban, 5 = Very rural

ADT $=$ Androgen Deprivation Therapy, $A S=$ Active Surveillance 